\title{
Laboratory Techniques Used to Diagnose Constitutional Platelet Dysfunction
}

\author{
Manal Ibrahim-Kosta ${ }^{1,2}$ Marie-Christine Alessi ${ }^{1,2}$ Nathalie Hezard ${ }^{2}$ \\ ${ }^{1}$ Aix Marseille University, INSERM, INRAE, Marseille Cedex 05, \\ France \\ 2 Laboratory of Hematology, CHU Timone, Marseille Cedex 05, France \\ Address for correspondence Marie-Christine Alessi, MD, PHD, \\ Aix Marseille University, 27 Boulevard Jean Moulin, 13005 Marseille, \\ France (e-mail: marie-christine.alessi@univ-amu.fr).
}

Hämostaseologie 2020;40:444-459.

Abstract

Keywords
- constitutional
platelet dysfunction
- diagnosis
- light transmission
aggregometry
- granule deficiency
- flow cytometry

Platelets play a major role in primary hemostasis, where activated platelets form plugs to stop hemorrhaging in response to vessel injuries. Defects in any step of the platelet activation process can cause a variety of platelet dysfunction conditions associated with bleeding. To make an accurate diagnosis, constitutional platelet dysfunction (CPDF) should be considered once von Willebrand disease and drug intake are ruled out. CPDF may be associated with thrombocytopenia or a genetic syndrome. CPDF diagnosis is complex, as no single test enables the analysis of all aspects of platelet function. Furthermore, the available tests lack standardization, and repeat tests must be performed in specialized laboratories especially for mild and moderate forms of the disease. In this review, we provide an overview of the laboratory tests used to diagnose CPDF, with a focus on light transmission platelet aggregation (LTA), flow cytometry (FC), and granules assessment. Global tests, mainly represented by LTA, are often initially performed to investigate the consequences of platelet activation on platelet aggregation in a single step. Global test results should be confirmed by additional analytical tests. FC represents an accurate, simple, and reliable test to analyze abnormalities in platelet receptors, and granule content and release. This technique may also be used to investigate platelet function by comparing resting- and activatedstate platelet populations. Assessment of granule content and release also requires additional specialized analytical tests. High-throughput sequencing has become increasingly useful to diagnose CPDF. Advanced tests or external research laboratory techniques may also be beneficial in some cases.

\section{Introduction}

Constitutional platelet dysfunction(CPDF) can induce a variety of bleeding disorders caused by defects in primary hemostasis. These defects may affect platelet adhesion, activation pathways, and aggregation. Platelet activation is a major phenomenon in primary hemostasis in which activated platelets form plugs in response to injuries to stop hemorrhaging. Platelet activation is initiated by platelet adhesion to the vessel wall, in which various platelet receptors bind to protein components of the injured vessel wall (e.g., glycoprotein [GP] VI binds to

collagen and GPIb-IX-V binds to von Willebrand factor [VWF] secreted from Weidel Palade bodies and adhering to collagen). Platelet adhesion triggers coordinated successive signaling pathways that yield full platelet activation, granule release essential for the amplification of the platelet response, platelet aggregation mediated by GPIIb/IIIa activation, ${ }^{1}$ and phosphatidylserine-exposing procoagulant activity. ${ }^{2,3}$

CPDF is associated with a wide spectrum of disorders, which are often difficult to diagnose and require a high degree of expertise in the field. Furthermore, CPDF may be associated with thrombocytopenia, which can impede and further (c) 2020 Georg Thieme Verlag KG
Stuttgart · New York
DOI https://doi.org/

10.1055/a-1223-3306. ISSN 0720-9355. 


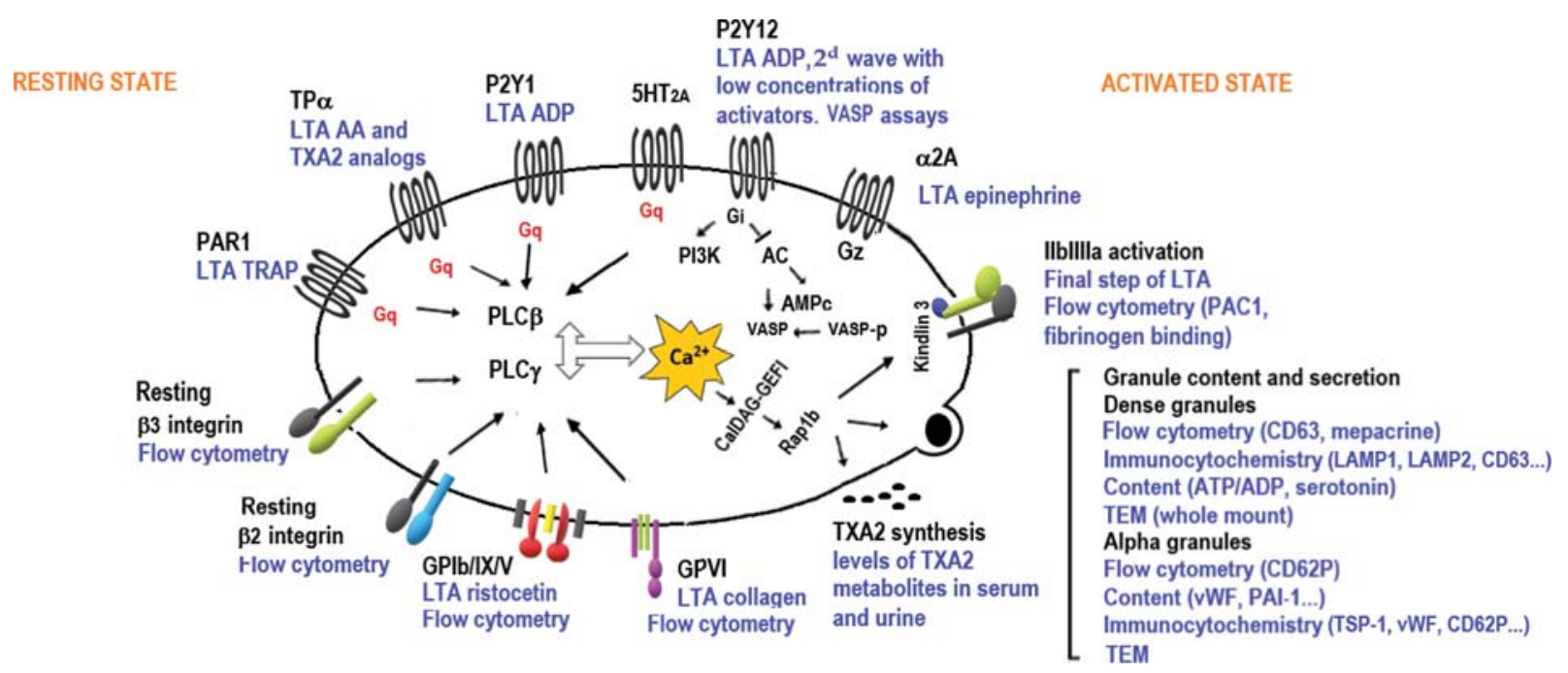

Fig. 1 Decision-making flow chart for the diagnosis of CPDFs. ADP, adenosine diphosphate; TRAP, thrombin-related activation peptide; PAC1, antibody that detects the neoepitope of active GPIIb/IIla; CD63, granulophysin; CD62P, P-selectin; PAI-1, plasminogen activator inhibitor 1; ATP, adenosine triphosphate; PS: phosphatidylserine; VASP: vasodilator-stimulated phosphoprotein; EM: electron microscopy; $T X A_{2}$, thromboxane $\mathrm{A}_{2}$; TEM, transmission electron microscopy.

complicate CPDF diagnosis. As some methods do not produce reliable results in samples with low platelet count, it is important to consider which methods can be used and which adaptations have to be made to secure the interpretation of the results in this particular setting.

CPDFs can also be associated with a genetic syndrome and is often marginalized; however, taking it into account may help establish the genetic syndrome diagnosis.

Key clinical elements to diagnose CPDF involve a careful medical and family history assessment including medications, which may indicate an acquired platelet dysfunction, and validated bleeding assessment scores to evaluate bleeding severity. ${ }^{4,5}$ Before considering a CPDF diagnosis, VWF disease, the most common disease associated with primary hemostasis defects, should first be ruled out (-Fig. 1). Laboratory tests used to identify CPDF are often suboptimal, which renders diagnosis complicated especially for mild and moderate forms of the disease. Diagnostic testing for CPDF should ideally be performed in a specialized laboratory under optimized preanalytical conditions and by experienced laboratory staff.

The full gamut of platelet properties cannot be analyzed in a single test. This review aims to provide an overview of the main laboratory tests used to diagnose CPDF, with a focus on light transmission platelet aggregation (LTA), flow cytometry (FC), and analysis of platelet granules.

\section{Global Platelet Functional Tests}

Global platelet functional tests refer to methods that analyze the consequences of platelet activation on platelet aggregation in a single step. When clinical results and family history indicate potential CPDF, platelet aggregation tests are initially performed in most cases, after ruling out coagulation and VWF defects. These global tests use various matricesplatelet-rich plasma (PRP) or whole blood (WB)-and have a variety of specifications and indications. In rare cases, it could be necessary to prepare washed platelets. ${ }^{6}$ This procedure is essential to isolate platelets from the anticoagulant and their plasma environment. This, for example, may help distinguish platelet type from plasma VWF disease. ${ }^{7}$ This article aims to describe the different approaches used to diagnose and characterize CPDF. A description of the main results of the platelet exploration is given in -Fig. 2 .

\section{Light Transmission Platelet Aggregation}

LTA is the most widely used global test for the diagnosis of CPDF. It detects abnormalities associated with increased bleeding in a significant proportion of individuals referred for CPDF assessment. ${ }^{8}$ This assay analyzes in vitro platelet aggregation in a GPIIb/IIIa-dependent manner by measuring the increased light transmission through dense PRP after addition of exogenous soluble activators except ristocetin. Ristocetin causes the binding of VWF to the GPIb complex leading to platelet agglutination. However, in patients suffering from GPIIb/IIIa deficiency, ristocetin-induced platelet aggregation is often reduced, reversible, and even cyclic indicating a contribution of GPIIb/IIIa in ristocetin-induced platelet aggregation. ${ }^{9,10}$

The kinetics of the response provides quantitative assessment of platelet aggregation. The assay read-out yields aggregation curves, including the slope of the curve, the peak extent (\%), and the latency time (lag phase). Additionally, the initial shape change, mono- or biphasic aggregation waves, and the stability of the aggregates (reversibility) can be visually assessed.

The LTA assay is still considered as the gold standard to test platelet function despite several limitations, including poor standardization, preanalytic constraints, the time-consuming nature of the assay, and the high sample volume requirement. As a result, several recommendations have been published in the past 10 years to guide LTA testing and interpretation of the results. ${ }^{10-13}$ International recommendations on preanalytical variables-blood collection, 

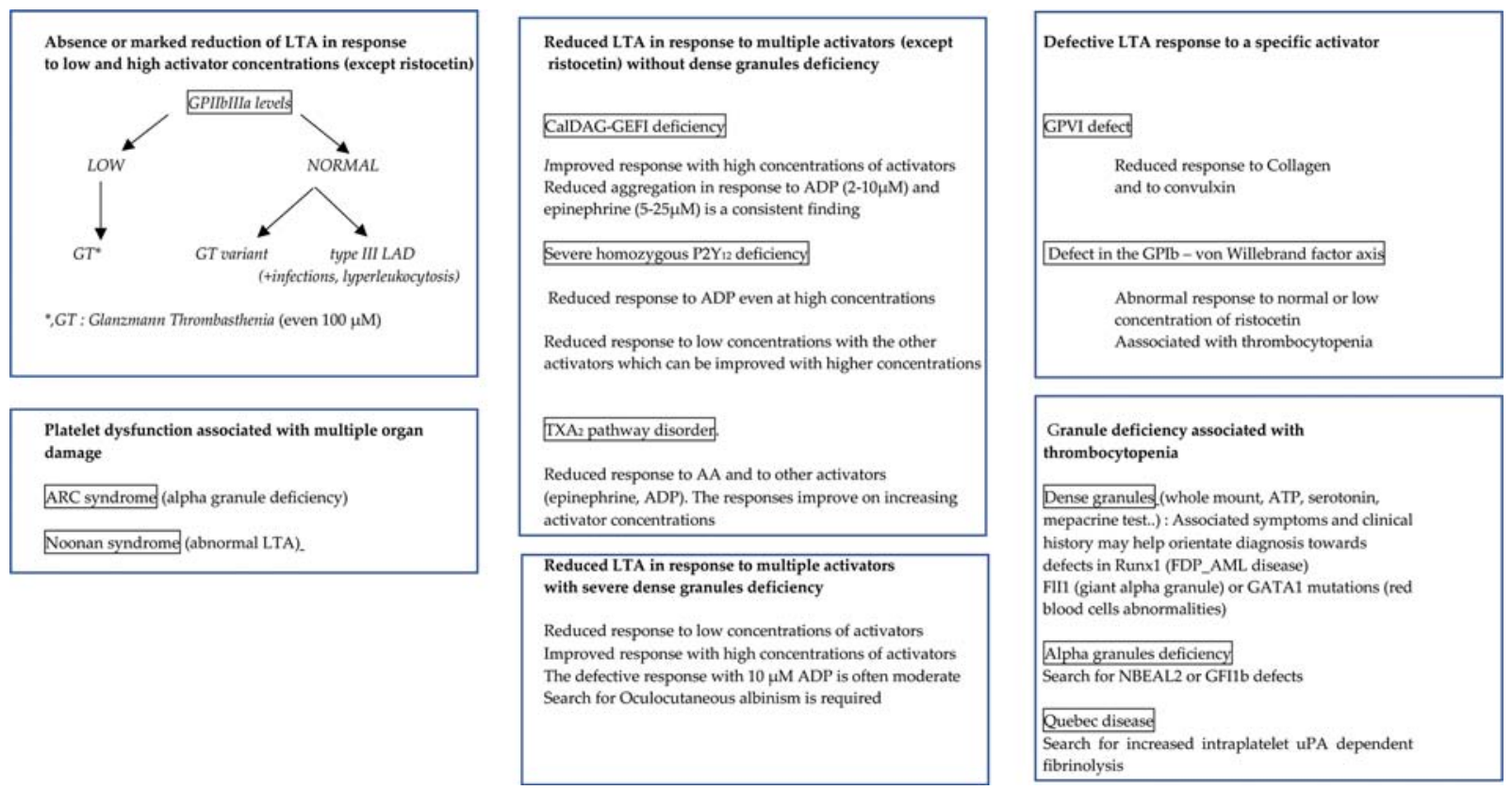

Fig. 2 Diagnosis orientation according to the results of platelet exploration. Only the major etiologies have been indicated. LTA, light transmission aggregation; GT, Glanzmann's thrombasthenia; LAD, leukocyte adhesion deficiency; ARC syndrome, arthrogryposis-renal dysfunction-cholestasis syndrome; ADP, adenosine diphosphate; $T_{X A_{2}}$, thromboxane $A_{2}$; AA, arachidonic acid; ATP, adenosine triphosphate; uPA, urokinase plasminogen activator.

preparation of PRP, assessment of PRP quality, methodology, choice of agonists, and evaluation and reporting of results of LTA-have been provided by the working party from the Platelet Physiology Subcommittee of Scientific and Standardization Committee/International Society of Thrombosis and Haemostasis (SSC/ISTH) on standardization of LTA. ${ }^{13}$ Among the most important recommendations are the maintenance of a PRP platelet count above $150 \times 10^{9} / \mathrm{L}$ below which the interpretation of the results will be not reliable. Blood samples should be drawn with minimal or no venostasis using an appropriate needle into polypropylene or siliconized glass tubes. PRP should be prepared by centrifuging blood samples at $\times 200 \mathrm{~g}$ for 10 minutes. Grossly hemolyzed and lipemic samples should be discarded. It is not recommended to adjust platelet count except in case of extreme high platelet count $\left(>500 \times 10^{9} / \mathrm{L}\right)$. Due to an inhibitory effect of platelet-poor plasma on platelet activation, platelet count adjustment with platelet-poor plasma should be avoided and replaced by dilution in buffer solution. ${ }^{14,15}$ PRP should be allowed to stand at room temperature for 15 minutes before testing. Studies should be completed within a maximum of 4 hours after blood sampling.

Platelet aggregation profiles vary depending on the activator used and the concentration. Therefore, appropriate activator concentrations must be selected to limit excessive interindividual variability and interpretation difficulties. A screening test starting with low activator concentrations, including aggregation induced by $2 \mu \mathrm{M}$ ADP, $5 \mu \mathrm{M}$ epinephrine, $2 \mu \mathrm{g} / \mathrm{mL}$ collagen, $1 \mathrm{mM}$ arachidonic acid (AA), thrombin receptor activating peptide (TRAP) $10 \mu \mathrm{M}$, and ristocetin $1.2 \mathrm{mg} / \mathrm{mL}$, in agreement with the ISTH recommendations, ${ }^{13}$ can provide an initial indication of platelet impairment. A second round of testing could include other activators and increased activator concentrations (less sensitive to platelet secretion) depending on the suspected diagnosis (e.g., ADP 5-100 $\mu \mathrm{M}$ : absence of response to $100 \mu \mathrm{M}$ ADP may help diagnose complete P2Y12 deficiencies; stimulation with the thromboxane A2 [TXA2] analog, U46619 $1 \mu \mathrm{M}$, enables the distinction between thromboxane prostanoid receptor and TXA2 synthesis deficiencies; convulxin is used as a GPVI-specific activator; TRAP $50 \mu \mathrm{M}$ is used to detect GPIIb/IIla activation abnormalities).

Defects in platelet aggregation may indicate reduced response to a single activator; although in most cases, the diagnostic process should assess reduced response to multiple activators, as the same signaling and amplification pathways are involved. A recent review has described the platelet aggregation profiles of the most frequently encountered CPDF disorders. ${ }^{12}$ A lack of aggregation in response to multiple activators at low or high concentrations, but maintained ristocetin response, indicates a GPIIb/IIIa defect, as GPIIb/IIIa activation is a required terminal step in the aggregation process (-Figs. 2 and 3; - Table 1). Glanzmann's thrombasthenia is associated with quantitative defects in GPIIb/IIIa. A variant of Glanzmann's thrombasthenia or Kindlin 3 deficiency (LADIII) ${ }^{16}$ is suspected when tests reveal an absence of platelet aggregation in response to all activators (except ristocetin) with preserved GPIIb/IIIa surface expression. The presence of a concomitant immune deficiency with hyperleukocytosis and infection indicates a Kindlin 3 deficiency $^{16}$ (-Table 1 ). Reduced platelet aggregation in response to several activators is frequently observed in clinical settings. A lack of response to low activator concentrations, but a normal or improved response to high activator concentrations, may suggest a CalDAG-GEFI deficiency, a nucleotide exchange factor for the GTPase Rap1B involved in the "inside-out" signaling pathway. ${ }^{17}$ Indeed, platelet 


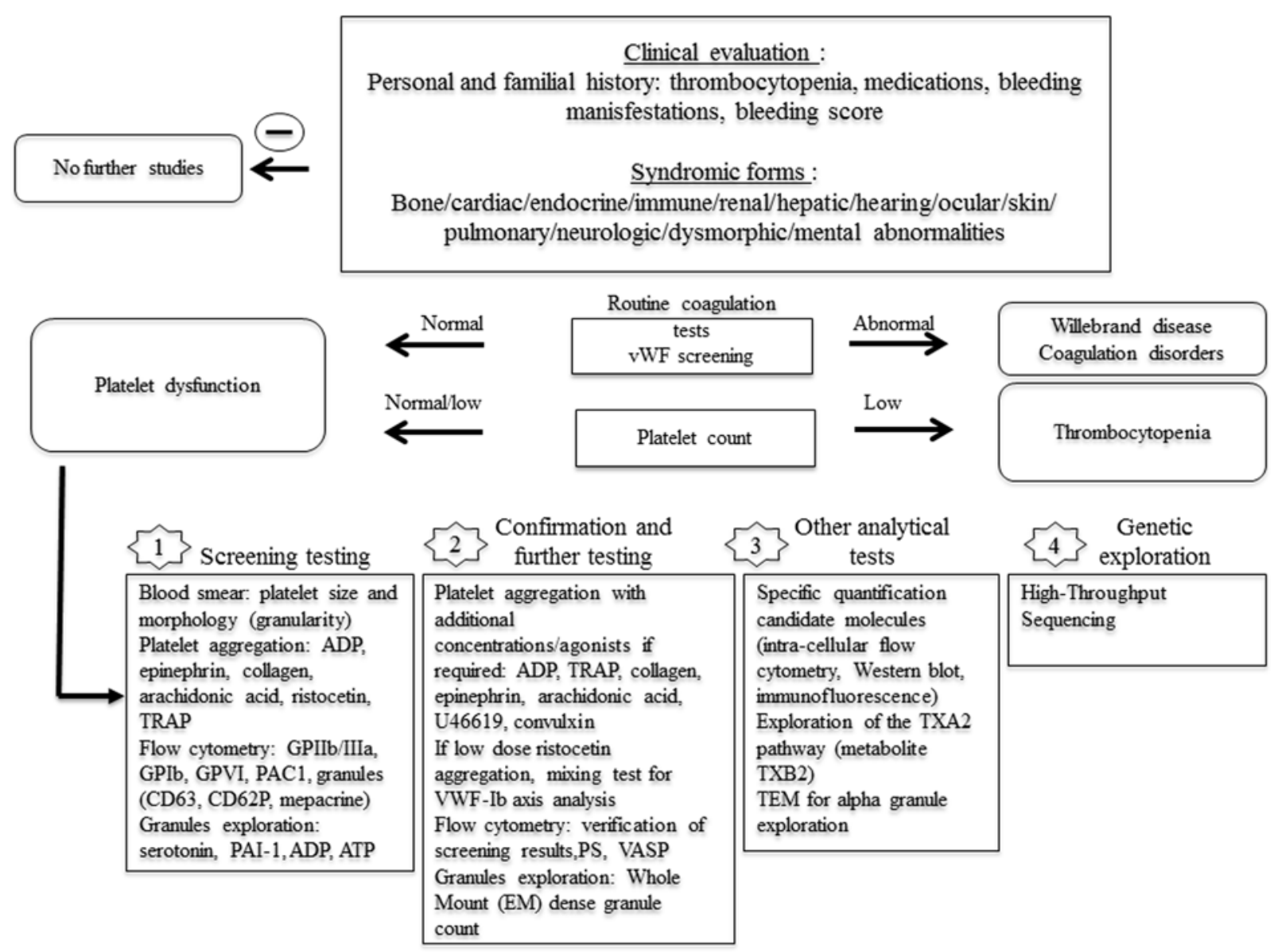

Fig. 3 Schematic representation of the primary platelet activation pathways and main clinical diagnostic tests for CPDF. Gq, G protein-containing subunit aq; $\mathrm{Gi}, \mathrm{G}$ protein-containing subunit $\alpha$; $\mathrm{Gz}$, G protein-containing subunit $\alpha \mathrm{s} ; \mathrm{ADP}$, adenosine diphosphate; ATP, adenosine triphosphate; AMPc, cyclic

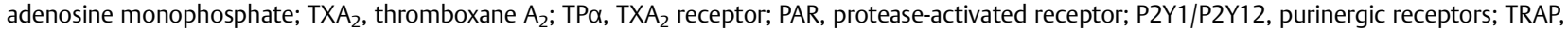
thrombin-related activation peptide; AA, arachidonic acid; PLC- $\beta$, phospholipase C- $\beta$; PLC- - , phospholipase C- - ; PI-3-K, phosphoinositide-3-kinase; AC, adenylate cyclase; Rap1b, Ras-related protein Rap-1b; $5 \mathrm{HT}$, 5 hydroxytryptamine (or serotonin); $5 \mathrm{HT}_{2 \mathrm{~A}}$, serotonin 5-HT $2 \mathrm{~A}$ receptors; VASP, vasodilatorstimulated phosphoprotein; LTA, light transmission aggregation; TEM, transmission electron microscopy; LAMP: lysosomal-associated membrane protein; PAC1, antibody that detects the neoepitope of active GPIIb/IIla; CD63, granulophysin; CD62P, P-selectin; PAl-1, plasminogen activator inhibitor 1; TPS-1, thrombospondin 1; VWF, von Willebrand factor. Procoagulant function of platelets is not presented in the figure as it involves different mechanisms. Among the most relevant are platelet activation with strong agonists and apoptosis. Plasma membrane phospholipids are asymmetrically distributed in resting platelets, with PS confined to the inner leaflet. After platelet activation by potent agonists (mainly thrombin associated with collagen), high levels of sustained intracellular calcium trigger scramblase activity. Apoptosis-induced PS exposure does not require increase in cytoplasmic calcium. Scramblase activation results in the loss of phospholipid asymmetry and PS exposure on the outer leaflet of the platelet membrane, providing the requisite surface for rapid thrombin generation.

activation involves two waves of activation. The first is sensitive to $\mathrm{Ca}^{2+}$ and CalDAG-GEFI, while PKC/ P2Y12 signaling in turn mediates a second wave of activation, necessary for sustained Rap1B activation and thrombus stabiliza$\operatorname{tion}^{18-20}$ ( - Fig. 3). CalDAG-GEFI deficiency primarily affects platelet activation induced by low-dose agonist activation involving the first wave of activation. ${ }^{21}$ This type of response may also correspond to abnormalities in the amplification pathway mediated by ADP. Reduced response to ADP even at high concentrations $(100 \mu \mathrm{M})$ has been observed in severe homozygous P2Y12 deficiency ${ }^{22-25}$ (-Table 1). In dense granule defects, substantial variability in LTA results has been observed with normal or reduced (or reversible) response to low concentrations of most activators (e.g., ADP, TXA2, and collagen) and improved response to high activator concentrations ${ }^{26}$ that is less dependent on the secretion-mediated amplification phenomenon.
Recently, a new inherited platelet bleeding disorder affecting the EPHB2 gene was described ( - Table 1). EPHB2 encodes the ephrin transmembrane receptor B2 tyrosine kinase. Platelet aggregation was absent in response to collagen and was impaired in response to $10 \mu \mathrm{M}$ ADP, $1.5 \mathrm{mM} \mathrm{AA}$, and $5 \mu \mathrm{M}$ U46619. ${ }^{27}$ Abnormality of the amplification pathway mediated by $\mathrm{TXA}_{2}$ also results in reduced response to several agonists primarily AA. This is most often due to an autosomal dominant variation in the gene coding the TP $\alpha$ receptor, TBXA2R, but can also correspond to a reduced conversion of exogenous AA to $\mathrm{TXA}_{2}$. This last condition is extremely rare. Mutations in TBXAS1, which encodes a thromboxane synthase, have been identified in patients with the rare autosomal recessive Ghosal hematodiaphyseal dysplasia (-Table 1 ). The use of $\mathrm{TXA}_{2}$ analogs, such as U46619 or STA2, as activators, and measurement of $\mathrm{TXB}_{2}$ levels (stable metabolite of $\mathrm{TXA}_{2}$ ) can help distinguish between these two mechanisms ${ }^{12}$ ( - Table 1 ). 


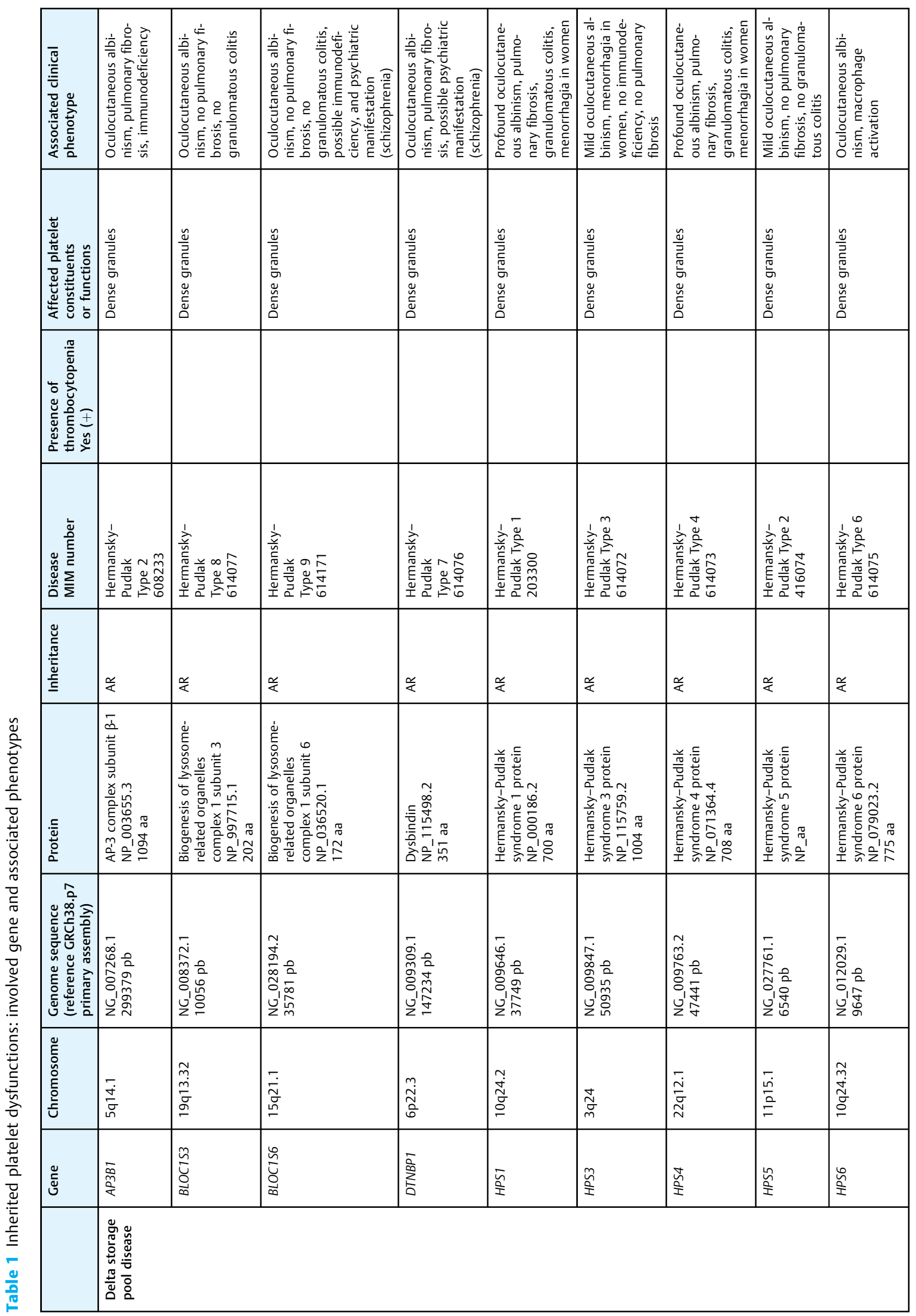




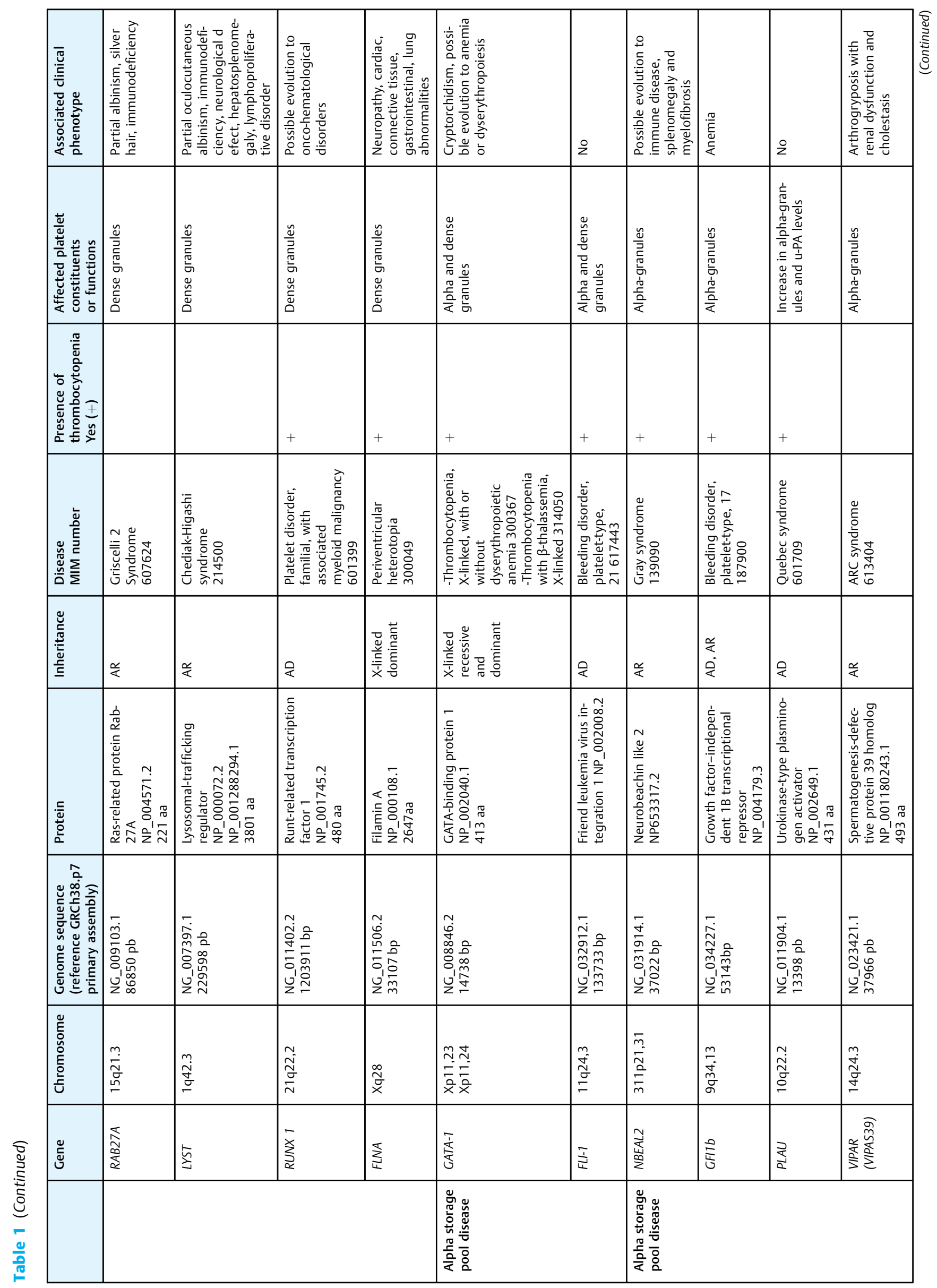




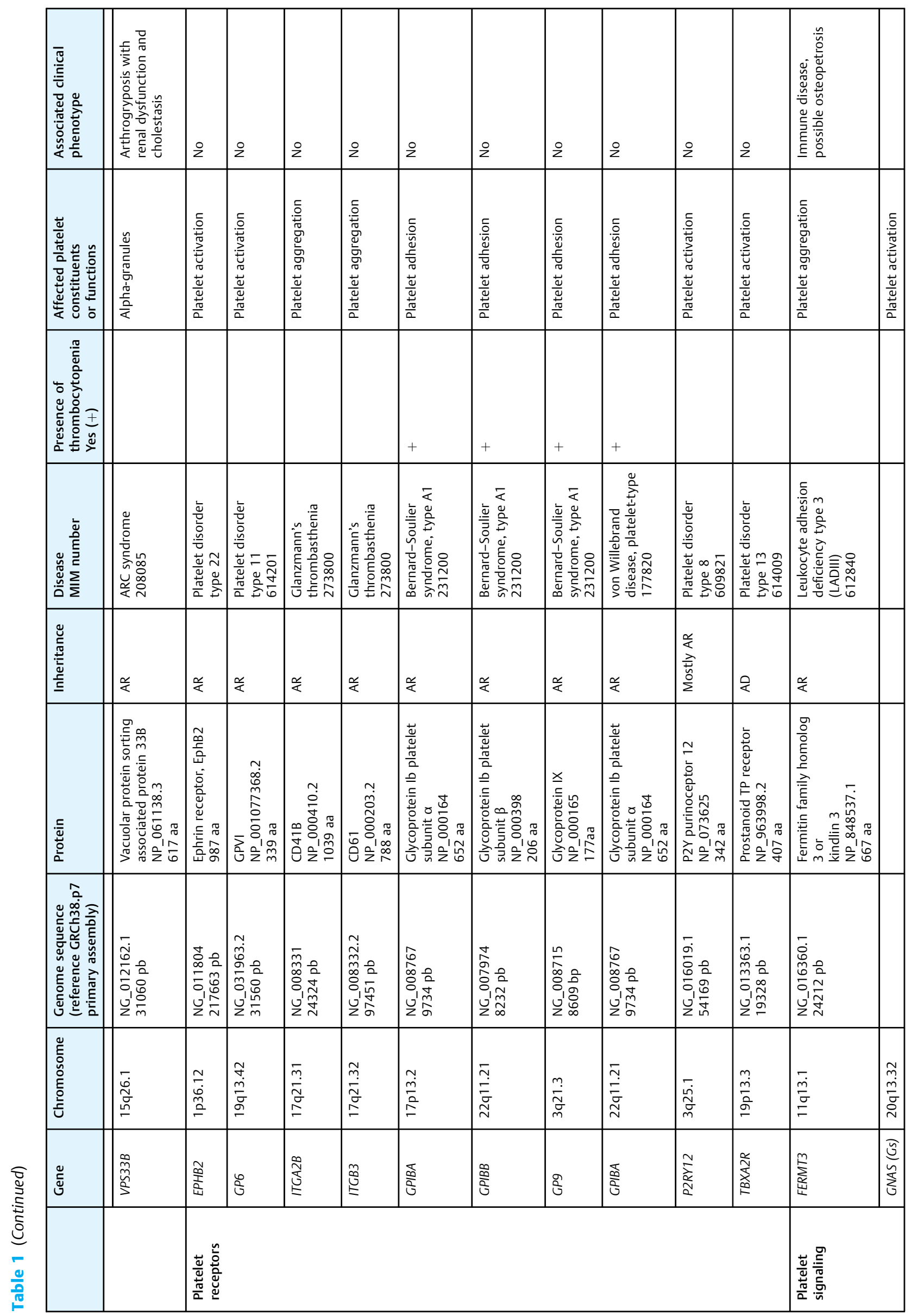




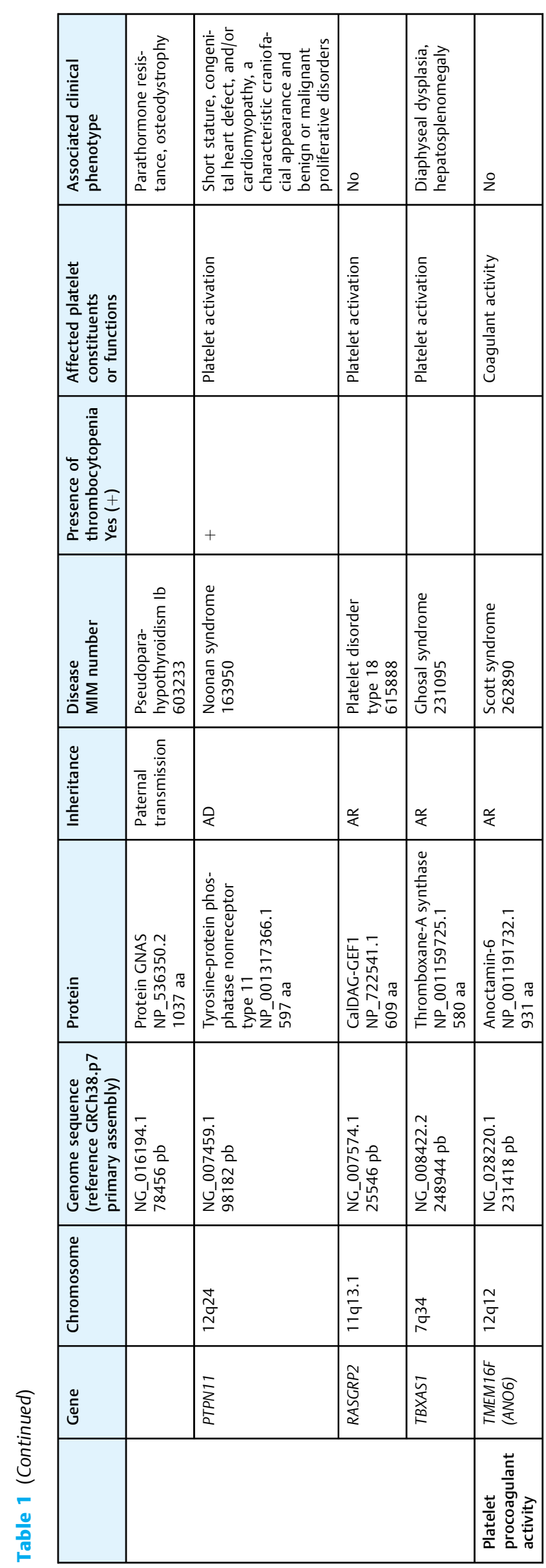

Defects in platelet aggregation response to a single activator are rare, similar to reduced response to collagen or ristocetin. Reduced response to collagen indicates a defect in GPVI, a major collagen receptor on the platelet surface ( - Table 1 ). Convulxin (extracted from snake venom) is a selective GPVI agonist that may help orientate the diagnosis. Noonan syndrome (NS) also displays a significant reduction in LTA induced by some activators. NS is an autosomal dominant genetic condition that affects one in 1,000 to 2,500 individuals; $50 \%$ of patients with NS display pathological variants of the PTPN11 gene $^{28}$ ( - Table 1). Ristocetin is an antibiotic that facilitates the binding of VWF to the GPIb-IX-V complex. Normal levels of both VWF and GPIb are necessary for proper aggregation. In the absence of VWF abnormalities, a lack of response to ristocetin suggests Bernard-Soulier syndrome, for which the main characteristic is macrothrombocytopenia and absence of or reduced GPIb levels at the platelet surface ${ }^{29}$ ( - Table 1 ). Low concentrations of ristocetin (e.g., $0.5 \mathrm{mg} / \mathrm{mL}$ ) do not induce platelet aggregation. With low-dose ristocetin treatment, abnormal aggregation with possible thrombocytopenia and platelet clumping suggests type $2 \mathrm{~B}$ or platelet type VWF disease due to a defect in platelet-VWF interactions. ${ }^{30,31}$

An increased susceptibility to bleeding has been described in patients exhibiting hyperactive Gs signaling. ${ }^{32}$ These cases are associated with syndromic clinical manifestations such as mental retardation, epilepsy, and moderately severe skeletal anomalies. LTA is normal, although bleeding time is significantly extended. The diagnosis is made by demonstrating increased inhibition of ADP-induced platelet aggregation by activators of receptors coupled to $\mathrm{Gs}$ such as $\mathrm{PGI}_{2}$ and $\mathrm{PGE}_{1}$ (-Table 1).

Physiological variations as well as unreported medications or xenobiotic agents can modify platelet behavior. Therefore, it is essential to confirm the results at least once, on different occasions ideally 2 to 6 months after the initial test, especially when the observed defects are moderate.

\section{Impedance-Based Whole-Blood Aggregometry}

Assessment of the changes in electrical impedance between two electrodes when platelet aggregation is induced can be performed on WB samples. Platelet aggregation is assessed by detecting the increase in electrical impedance recorded in Ohms. ${ }^{33}$ WB aggregometry (WBA) is technically simple; the operator adds an activator directly to the WB sample and subsequently records the rise in impedance as platelets coat electrodes suspended in the blood. ${ }^{33,34}$ Compared with LTA, WBA involves more physiological conditions (includes other blood elements involved in platelet function, and aggregation takes place on surfaces). Additionally, WBA requires a relatively smaller volume of WB and no sample manipulation, thereby enabling a rapid analysis of platelet function. Fritsma and McGlasson have summarized the main preanalytical conditions for impedance-based WBA. Citrated blood (3.2\% citrate) must be tested within 4 hours of collection. Blood sample has to be diluted. A sample whose platelet count is between 50 and $100 \times 10^{9}$ may be assayed undiluted; if the platelet count is below $50 \times 10^{9}$, WBA should not be performed. ${ }^{34-37}$ In contrast to LTA, WBA is unaffected by icterus and lipemia. WBA is 
also unaffected by hemolyzed and lipemic samples but is sensitive to hematocrit and platelet and leukocyte counts. ${ }^{10}$ In studies comparing LTA and WBA, the WB impedance multiplate analyzer yielded very similar results to LTA assays in populations of patients suffering from Glanzmann's thrombasthenia. ${ }^{38,39}$ However, WBA is more expensive and less widely used than LTA. Clearly, the utility of WBA should be more extensively investigated for the diagnosis of CPDF.

\section{Bleeding Time and Platelet Function Analyzer 100/200}

The bleeding time test is the only available in vivo primary hemostasis test that integrates platelet function, VWF, and the blood vessel wall. It is an easy and rapid test in which the time it takes for bleeding to stop (platelet plug formation) in an in vivo skin wound is recorded. ${ }^{40}$ For many years, the bleeding time test has represented the only screening test to identify congenital and acquired platelet disorders. ${ }^{41}$ However, routine use of this test has recently declined due to several factors, including poor standardization and accuracy, the invasive nature of the test, operator-based variations, and variations resulting from differences in skin thickness and temperature among patients. ${ }^{10}$ This test is no more recommended. However, it is to note that bleeding time may help orientate diagnosis in very peculiar situation such as increased response to endothelium-dependent platelet inhibition that is not easily detected with LTA. ${ }^{32}$ The PFA-100 and PFA-200 systems (Siemens) have been proposed as simple and rapid automated screening tests for primary hemostasis impairments. The platelet function assay employs high shear stress and citrated WB to simulate in vivo platelet adhesion to VWF. The analyzers measure the platelet closure time of a microscopic aperture composed of a collagenADP or collagen-epinephrine-impregnated membrane ${ }^{42}$ with a fixed concentration of activators. The PFA-100/200 is sensitive to platelet count and hematocrit (PFA-100/200 should not be performed when platelet count is less than $100 \times 10^{9} / \mathrm{L}$ or hematocrit $<0.30)$. Closure time may be shortened in case of high platelet count $\left(>500 \times 10^{9} / \mathrm{L}\right)$ or elevated VWF levels. ${ }^{43}$ For a full description of the preanalytical constraints and results interpretation, see the article by Harrison et al. ${ }^{10}$

The PFA-100 is not specific for any particular primary hemostasis disorder. Normal closure times enable to exclude VWF disease with high sensitivity ${ }^{44}$ except type 2 N. Prolonged closure times in the absence of VWF disease may indicate a severe form of CPDF such as Glanzmann's thrombasthenia, Bernard-Soulier syndrome, or platelet type von Willebrand disease thrombasthenia ${ }^{10,45}$ Closure time tests lack specificity and sensitivity for milder forms of CPDF, similar to bleeding time. ${ }^{45}$

\section{Other Whole-Blood Assays}

The Impact-R system (DiaMed, Cressier sur Morat, Switzerland) is a WB assay used to evaluate platelet function under arterial conditions with a cone and plate technology. Once blood samples are aliquoted into a polystyrene well, plasma proteins immediately adhere to the well surface, thereby resulting in platelet adhesion and aggregation. Following the removal of excess of blood and staining from the adhered platelets, the surface area
(\%) covered by platelet aggregates (adhesion index) and the size of platelet aggregates (aggregation index) are assessed using an image analyzer. This automated method does not require sample preparation and is able to analyze low sample volumes. The Impact- $R$ agonist response test has been used to detect aggregation defects in patients with storage pool disease, severe von Willebrand disease, and epinephrine response deficiency. ${ }^{46}$ Additional studies should be conducted to explore its application in the diagnosis of the whole spectrum of CPDF disorders. Many other tests have been developed mainly to evaluate the primary hemostasis status of patients in acute and critical care settings. However, some tests are either inflexible and not well adapted for CPDF diagnosis (as observed with the PFA-100) or have never been evaluated in this particular context. For example, the Global Thrombosis Test (GTT; Montrose Diagnostics Ltd., London, UK) is performed by using native non-anticoagulated WB, without adding activators. Platelet activation is only induced by high shear stress similar to that in coronary arteries. ${ }^{47}$ Plateletworks (Helena Laboratories, Beaumont, Texas, United States) is an in vitro diagnostic, point-of-care test platform that is based on quantifying platelets before and after platelet aggregation. The Plateletworks assay demonstrates the clinical value of measuring both platelet count and function. Reduced platelet counts reflect the extent of activated platelets that have aggregated. However, the Plateletworks assay is inflexible and technically challenging to operate, as the test must be performed within a few minutes, which is also the case with the GTT. ${ }^{48}$ Thromboelastometry provides a viscoelastic measurement of clot formation in WB samples. This method has been developed to test for fibrinogen and severe coagulation factor deficiencies, hyperfibrinolysis, and platelet-fibrin interactions, as previously described. ${ }^{47}$ This method is primarily used to monitor excessive postoperative bleeding and the need for blood products during cardiac surgery. Rotational thromboelastometry (ROTEM) is an established viscoelastic method for hemostasis testing. This system could be helpful to guide the physician regarding any need for platelet transfusion or other adjunct therapies notably during Glanzmann's thrombasthenia. ${ }^{49}$ When treating patients with congenital or acquired platelet dysfunction, some intrinsic limits of thromboelastometry to assess platelet function may be overcome with the combined use of a point-of-care device that also measures platelet aggregation. ${ }^{50,51}$

Recently, the "in vitro thrombosis model" 52 has been presented as an ambitious technique used to screen for CPDF disorders, in which anticoagulated WB is perfused over fibrillar collagen in glass microcapillaries or parallelplate flow chambers to monitor the formation of threedimensional aggregates. This model enables analysis of the four main stages of platelet thrombus formation-i.e., platelet tethering, adhesion, activation, and aggregationunder a wide range of hemodynamic conditions. Recommendations for standardization of these models have recently been published by the Subcommittee on Biorheology of the ISTH. ${ }^{53}$ 


\section{Analytical Tests}

Platelet dysfunction disorders may arise due to a variety of root causes. As a result, to properly make a diagnosis, global test results (often using LTA) should be confirmed by additional analytical tests. These tests should aim to analyze the following: (1) reduced expression levels of platelet surface receptors or key intraplatelet molecules; (2) defects in platelet activation, primarily by assessing the evolution of receptors in response to activation or signaling events; and (3) reduced levels of platelet granules.

\section{Flow Cytometry}

FC is used to distinguish between circulating cells and analyze specific cell populations of interest. It is a widely used technique to rapidly analyze many aspects of platelet biology and function. Briefly, platelets in PRP or WB are labeled with fluorochrome-tagged monoclonal antibodies (mAbs) with affinity against a selection of platelet-specific antigens (-Fig. 3 ). Platelets are identified by using a fluorochrome-conjugated platelet marker or by assessing the characteristic scatter properties (forward scatter corresponds to platelet size, while side scatter corresponds to platelet granularity). The light from the laser excites all fluorescent molecules associated with platelets, and emitted fluorescence is then collected, amplified, and converted into an electronic signal. The fluorescence signal is directly proportional to the density of the antigen of interest. The results are expressed either as median of fluorescence or as an absolute number of $\mathrm{mAbs}$ bound per platelet. The technique enables the analysis of PRP or WB without previous separation steps (minimal preanalytical artifacts, small volumes of blood samples which is particularly interesting for studies involving young children/neonates), ${ }^{54,55}$ and multiple fluorochromes (antigens) simultaneously in a single sample. Furthermore, FC provides accurate analysis of severe thrombocytopenia cases, such as Bernard-Soulier syndrome. ${ }^{56} \mathrm{FC}$ is an important technique used to diagnose CPDF disorders by assessing cell surface membrane receptor deficiencies-e.g., Glanzmann's thrombasthenia (abnormal or lack of binding of fluorescentlabeled IIb- or IIIa-specific mAbs), ${ }^{57}$ Bernard-Soulier syndrome (abnormal or lack of binding of fluorescent-labeled GP1b-, GPIX-, or GPV-specific mAbs), ${ }^{56}$ and less common CPDF disorders, such as those involving defects in the GPVI receptor. ${ }^{58}$ Increased expression of platelet surface receptors (GPIIb/IIIa) and receptor internalization (GPIb) can be evaluated by comparing resting and activated state platelet populations. ${ }^{59}$ In addition to GP, which is constitutively expressed on the resting platelet membrane, several other markers can be detected on the platelet surface only after platelet activation: PAC1 antibody and fibrinogen are bound following activation-induced conformational changes in GPIIb/IIIa, granulophysin (CD63) is detected after dense granule release, and P-selectin (CD62P) is detected after alpha-granule release. ${ }^{54,60} \mathrm{FC}$ can be used to measure the fluorescence of mepacrine, which binds adenine nucleotides selectively with high affinity. The analysis of mepacrine uptake and release is used to evaluate dense granule deficiency as detailed later ("Dense granule deficiency"). FC is also a valuable technique to diagnosis Scott's syndrome, which is characterized by a translocation defect of the anionic aminophospholipid phosphatidylserine on the platelet surface after platelet activation, ${ }^{61}$ leading to a reduced procoagulant activity and a bleeding diathesis. Besides Scott's syndrome, a very rare syndrome, FC is of particular interest to recognize the subpopulation of procoagulant platelets exposing PS in association with high levels of coagulation factors. They are observed in vitro after dual agonist stimulation with collagen and thrombin (COAT platelets) and represent approximately $32 \%$ of all platelets in controls. ${ }^{62,63}$ Methods to quantify coated platelets have been described by different groups. ${ }^{63,64}$ Lower levels of coated platelets were reported in intracerebral hemorrhage, ${ }^{65}$ and in human and animal studies focused on bleeding diatheses. ${ }^{66-68}$ Identification of increased coated platelets may improve the ability to identify patients at high risk of recurrent stroke. ${ }^{69}$ Furthermore, FC may be used to assess intraplatelet signaling, in which platelets must be permeabilized prior to labeling. Signaling downstream P2Y12 involves vasodilator-stimulated phosphoprotein (VASP). Evaluation of VASP phosphorylation in response to ADP may help diagnose functional defect in P2Y12. ${ }^{70}$

\section{Assessment of Platelet Granule Content and Release}

Two types of platelet storage granules are typically analyzed: electron-dense granules and alpha-granules. Dense granules belong to the family of lysosome-related organelles. Each platelet contains three to eight dense granules, which store cations $\left(\mathrm{Ca}^{2+}, \mathrm{Mg}^{2+}, \mathrm{K}^{+}\right)$, polyphosphate and pyrophosphate esters (ADP, ATP, GTP), and bioactive amines (serotonin [or 5hydroxytryptamine, 5HT] and histamine). During platelet activation, the release of dense granules is involved in hemostasis and is indispensable for the formation of a stable aggregate. ${ }^{71-73}$ Defective nucleotide signaling can account for platelet function disorders that result in severe bleeding. ${ }^{74}$ Calcium is responsible for the electron density of these granules when viewed via electron microscopy (EM). Alphagranules are more abundant (50-80 per platelet) than dense granules, and they contain a large variety of proteins including adhesive proteins, coagulant and anticoagulant factors, chemokines, and growth factors. Alpha-granules are involved in clot formation and vascular repair. ${ }^{75}$ The identification of granule defects remains a challenge ${ }^{76,77}$ and requires a variety of tests.

Dense granule deficiency. As global tests may yield normal results for patients with dense granule deficiency (most common type of platelet granule disorder ${ }^{78}$ ), appropriate methods are required for diagnosis, including granule quantification and assessment of granular constituents, both before and after activation to examine platelet release reactions. Methods for diagnosis of dense granule deficiency are based on a wide range of techniques including luminometry, FC, ELISA, radio-isotopic assays, and high-performance liquid chromatography (HPLC), which can be coupled with tandem mass spectrometry (LC-MS/MS), fluorescent microscopy, and electron microscopy (-Fig. 3).

Nucleotide quantification. Platelets contain two separate nucleotide pools: a metabolically active pool primarily composed of ATP and a secretory pool with equal levels of ATP 
and ADP released by dense granules. While ATP (3.5$5.9 \mathrm{nmol} / 10^{8}$ platelets) plays a limited role in aggregation, ADP (1.9-3.8 nmol $/ 10^{8}$ platelets) plays a major role in the amplification pathway by binding to P2Y12. Luminometry is widely used to quantify nucleotides. In the context of nucleotide quantification in platelets, the platelets are activated by various agonists and released ATP and then react with luciferin-luciferase reagent, thereby yielding a light signal proportional to the ATP concentration. This technique presents several major advantages: assays can be conducted directly on PRP or WB and it is highly sensitive. The lumiaggregometer has also been developed to simultaneously assess platelet aggregation and ATP release in samples of PRP, WB, or washed platelets. ${ }^{79}$ However, this technique does not detect ADP release, which may pose a problem for selective defects in dense granule ADP transport associated with bleeding and normal levels of ATP and serotonin but reduced ADP levels (as described in dogs). ${ }^{80}$ ADP can only be quantified after phosphorylation to ATP by creatine kinase and creatine phosphate, which serves as a phosphate donor in the conversion of ADP to ATP. ATP, ADP, and AMP can also be directly and simultaneously quantified using HPLC or LC-MS/MS. ${ }^{81}$ The evaluation of the ATP:ADP ratio (e.g., normal $>2$ ) appears to be the best method to detect reduced ADP levels. Selecting the appropriate type and/or concentration of activator(s) to stimulate dense granule release is crucial, as this impacts the performance of the quantification assay. Pai et al have recommended the application of three agonists in high concentrations, which reduces intra-assay variability as well as intra- and intersubject variability. ${ }^{82}$ The diagnosis of secretion defects is more accurate when abnormal nucleotide release is demonstrated with several agonists and confirmed on several occasions. ${ }^{82}$ Evidence-based guidelines are needed to use and interpret these results considering the high variability observed between patients and healthy controls. ${ }^{83}$

Flow cytometry. As mentioned earlier, FC is used to analyze dense granules, by assessing platelet granulophysin (CD63) surface expression levels before and after activation as well as mepacrine uptake and release. Several reports have emphasized the relevance of the mepacrine test to assess storage pool disease. ${ }^{84-87}$ Platelet mepacrine uptake occurs rapidly, with near maximum incorporation within 1 minute. After 1 minute, the incorporated mepacrine is located in a pool, most of which is released by thrombin. The thrombin-induced release of mepacrine from dense granules increases within the first 5 minutes, until levels plateau at 15 minutes. ${ }^{88}$ Platelet dense granule release capacity is estimated by subtracting mepacrine uptake levels after stimulation from that of the nonstimulated sample. Recently, FC analysis of mepacrine fluorescence has been compared with platelet ATP/ADP content assays as a reference test. Mepacrine fluorescence assays appear effective to rule out dense granule deficiency and may be proposed as an easy and convenient technique to identify patients who require further extensive testing. ${ }^{89}$ Furthermore, dense mepacrine-labeled granules can be directly observed and quantified using fluorescent microscopy, which enables the quantification of granules per platelet. The results are expressed as a distribution curve, which is compared with the distribution curve of a control sample analyzed in parallel..$^{90}$

Serotonin quantification. Various assays are used to measure serotonin levels in platelets. The most direct and simple method involves quantification of serotonin by electrochemical detection after HPLC separation on serum or PRP samples. ${ }^{91}$ Alternatively, serotonin levels may be accurately quantified via ELISA, fluorometry, fluorescent microscopy, and FC on fresh or frozen PRP samples, depending on the method used. ${ }^{91,92}$ Antidepressant drugs that inhibit 5-HT reuptake have been associated with a marked decrease in platelet 5-HT levels, leading to acquired 5-HT deficiency. Secretion of radio-labeled serotonin $\left({ }^{14} \mathrm{C}\right.$-serotonin) from prelabeled platelets in response to agonist stimulation is a sensitive test that can be used in laboratories that handle radioactivity. ${ }^{93}$ As platelet serotonin and nucleotide levels are not necessarily correlative, assessment of serotonin levels cannot be substituted by nucleotide quantification assays.

Whole-mount electron microscopy. This technique involves an assessment of unfixed/unstained platelets to directly visualize electron-dense granules for quantification. Briefly, platelet samples are prepared by aliquoting a drop of PRP onto a Formvar-coated grid, washing the platelets with distilled water, and then air-drying the grid. The sample is then examined by EM to determine the average number of electron-dense granules in 30 to 50 platelets. Samples may be shipped to a specialized laboratory for analysis without any preanalytical concerns, as reported in an External Quality Assessment survey. ${ }^{94}$ High intra-subject variability has been observed in cases with a mild reduction in dense granule content, contrary to non-dense granule deficiency cases. Thus, patients presenting with reduced levels of dense granules per platelet must be retested, on a new sample, to confirm the diagnosis. Although dense granule counts are similar in pediatric and adult patients, the diagnosis of dense granule deficiency in very young children requires repeat testing to confirm the results at older age. ${ }^{95}$ Recently, super-resolution light fluorescent microscopy analysis of CD63-stained platelets has been proposed as an alternative to EM, to potentially facilitate the automation of the quantification process, enable rapid quantification of many platelets per patient, and provide statistically robust discrimination between control and patient samples. Super-resolution light fluorescent microscopy is also less expensive. ${ }^{96}$

As there is no single test to diagnose dense granule defects, a combination of methods is recommended to distinguish between quantitative defects (reduced dense granule numbers) and qualitative defects (abnormal content). Normal basal levels that decrease after stimulation suggest a platelet signaling abnormality rather than a specific granule defect. Additional studies are required to evaluate the prevalence and characteristics of the different categories of storage pool disease.

Dense granule deficiency can occur in isolation ( $\delta$-storage pool disease, $\delta$-SPD), combined with alpha-granule deficiency $\left(\alpha / \delta\right.$-SPD) and as part of a syndrome. ${ }^{97,98}$ Patients with Hermansky-Pudlak syndrome (HPS) exhibit bleeding diathesis caused by dense granules deficiency and hypopigmentation 
of skin, hair, and eyes due to melanosome defects. ${ }^{99}$ There are several well-established HPS types labeled according to the gene that is mutated and numbered chronologically with their discovery ( $\rightarrow$ Table 1 ). Individuals suffering from ChediakHigashi syndrome (CHS) have bleeding diathesis due to dense granule deficiency as well as decreased pigmentation and severe immune deficiency due to malformation of additional lysosome-related organelles. CHS patients have giant intracellular organelles that are pathognomonic of the disease. ${ }^{100} \mathrm{CHS}$ is caused by mutation of the LYST gene. HPS and CHS are uncommon, autosomal recessive diseases. Griscelli syndrome type 2 is a $\mathrm{CH}$-like syndrome. It is a rare cutaneous disease characterized by a silvery-gray sheen of the hair and hypopigmentation of the skin, which can be associated with immunologic impairment and dense granule deficiency ${ }^{98}$ ( - Table 1). Dense granule deficiency has also been associated with thrombocytopenia due to mutations in transcription factors (GATA1, ${ }^{101}$ FLI $1{ }^{84}$ and RUNX $1^{102}$ or in filamine A [FLNA ${ }^{103}$; - Fig. 2, - Table 1).

\section{Alpha-Granule Deficiency}

Several techniques are used to examine alpha-granules. The absence of alpha-granules in platelets results in large pale platelets as observed via light microscopy. FC is the most commonly used assay to assess alpha-granule deficiency. This technique can be used to analyze activated platelets for expression of P-selectin (CD62P), an alpha-granule transmembrane protein expressed at the platelet surface. ELISA can be used to detect secreted alpha-granule content (i.e., platelet factor $4, \beta$-thromboglobulin, and plasminogen activator inhibitor 1 [PAI-1]). Analysis of PAI-1 antigen is of particular interest because $95 \%$ of serum PAI-1 derives from platelets and PAI- 1 antigen exhibits high stability in serum, which is useful when samples are frozen and shipped to a specialized laboratory. Transmission EM continues to be an important technology in the field of platelet research. Although the technique is relatively costly, it is the method of choice to evaluate alpha-granule abundance. Transmission EM is often used to confirm the diagnosis of alpha-granule deficiency after initial tests indicate abnormal results. ${ }^{11,104}$ However, special training is required to operate a transmission EM and analyze the results, and the system consists of large and cumbersome instruments that require special housing and maintenance (-Fig. 3 ).

Alpha-granule abnormalities may occur in isolation, as it is the case with the gray platelet syndrome (NBEAL2 or GFI1b variant), combined with dense granule deficiency (GATA1 or FLI1 variants) and as part of a syndrome (arthrogryposisrenal dysfunction-cholestasis [ARC] syndrome; -Fig. 2, - Table 1). ARC syndrome is multisystem disorder caused by mutations in the VPS33B or VIPAR gene and associated with congenital joint contractures, renal tubular dysfunction, and cholestasis. ${ }^{105}$

\section{Other Analytical Tests}

To refine the diagnosis of CPDFs, complementary tests may be helpful in some cases, such as specific assessment of suspected deficient proteins by immunoblot assays or intracellular FC.
For example, the LADIII- and RASGRP2-related diseases are primarily associated with a complete deficiency in Kindlin 3 and CalDAG-GEFI, respectively, which can be detected by immunoblot assay. Intracellular FC can be used to determine the phosphorylation status of key proteins in signaling pathways. ${ }^{106}$ Recently, immunofluorescence labeling of blood smears has been proposed as an alternative approach allowing to diagnose approximately $30 \%$ of patients with suspected CPDF. ${ }^{107}$ Advantages of this approach are the preanalytical requirements $(<100 \mu \mathrm{L}$ venous or capillary blood), which makes the method suitable for diagnosis in pediatric patients, including neonates, and in patients presenting thrombocytopenia. The choice of the panel of antigens (e.g., thrombospondin-1, VWF, P-selectin for alpha-granules; Lamp1, Lamp2, and CD63 for dense granules) may identify Glanzmann's thrombasthenia, Bernard-Soulier syndrome, gray platelet syndrome, GATA1 and GFI1B macrothrombocytopenia, and filamin Arelated thrombocytopenia. This method is of particular interest for laboratories without access to high-throughput sequencing (HTS). Several tests may be used to measure serum and urine levels of TXA $A_{2}$ metabolites. This is useful to evaluate platelet function and detect defects in $\mathrm{TX}_{2}$ production, which is essential for the amplification of platelet activation. ${ }^{108-110}$ Quebec platelet disorder involves a gain-of-function mutation of the urokinase plasminogen activator, which causes plasmin-mediated proteolysis of platelet alpha-granule content and hyperfibrinolysis. This syndrome is a rare, autosomal dominant bleeding disorder that has been described in a family from Quebec Province in Canada. ${ }^{111,112}$ These patients experience joint bleeding, hematuria, and large bruises. Although platelet morphology and alpha-granule levels are normal in Quebec platelet disorder patients, platelet urokinase is 100 times higher in patients as compared with controls. ${ }^{113,114}$

\section{High-Throughput Sequencing}

HTS has recently been introduced into clinical diagnostic laboratories that study constitutional platelet disorders, thereby resulting in major advances in the field. This approach primarily involves targeted gene panel tests or whole-exome sequencing. HTS has already made a significant contribution to the improvement and expansion of molecular diagnosis and enhanced the understanding of platelet pathophysiology. ${ }^{115}$ This technique enables the rapid identification of genes associated with platelet disorders ( - Table 1). It has also become less expensive and increasingly accessible. HTS could be critical in the diagnosis of patients with chronic and familial mucocutaneous hemorrhagic symptoms in whom a platelet disorder is suspected. Functional assays could be subsequently performed to evaluate the pathogenicity of genetic variants identified via sequence analysis. Further research would be useful to determine the best place of HTS from a socioeconomic perspective. However, the expansion of HTS assays has raised several concerns regarding variant interpretation and the ethical implications of detecting incidental findings. For these reasons, only clinical experts in CPDF physiopathology and those aware of the phenotype-genotype relationship and ethical issues 
should be involved in the analysis and interpretation of HTS results.

\section{Conclusion}

Diagnosis of CPDF is a multistep process that begins with a careful assessment of personal and family medical history, followed by specialized platelet assays and genetic tests. CPDFs are implicated in a wide spectrum of disorders, for which diagnosis is often a significant challenge even for specialized laboratories. Moreover, most platelet functional tests lack standardization, and quality control tests are becoming an increasingly important issue. The implementation of HTS approaches to diagnose CPDF has resulted in major advances in the field. HTS represents a valuable method to confirm diagnoses, but it also introduces ethical issues that highlight the necessity to discuss expectations prior to testing. Therefore, platelet assessment tests should be conducted in specialized centers, where platelet function tests can be properly performed and interpreted. In cases when appropriate clinical and gene panel tests fail to yield an accurate diagnosis, external research laboratories may be involved for further platelet analysis, provided that patient consent is obtained. This may be a powerful opportunity to enhance the understanding of undiagnosed rare platelet disorders and facilitate the development of new diagnostic options.

\section{Conflict of Interest}

The authors declare, that they have no conflict of interest.

\section{References}

1 Gremmel T, Frelinger AL III, Michelson AD. Platelet physiology. Semin Thromb Hemost 2016;42(03):191-204

2 Agbani EO, Poole AW. Procoagulant platelets: generation, function, and therapeutic targeting in thrombosis. Blood 2017;130 (20):2171-2179

3 Reddy EC, Rand ML. Procoagulant phosphatidylserine-exposing platelets in vitro and in vivo. Front Cardiovasc Med 2020;7:15

4 Gresele P, Orsini S, Noris P, et al; BAT-VAL Study Investigators. Validation of the ISTH/SSC bleeding assessment tool for inherited platelet disorders: a communication from the platelet physiology SSC. J Thromb Haemost 2020;18(03):732-739

5 Tosetto A, Castaman G, Rodeghiero F. Bleeding scores in inherited bleeding disorders: clinical or research tools? Haemophilia 2008;14(03):415-422

6 Patscheke H. Shape and functional properties of human platelets washed with acid citrate. Haemostasis 1981;10(01):14-27

7 Hechler B, Dupuis A, Mangin PH, Gachet C. Platelet preparation for function testing in the laboratory and clinic: historical and practical aspects. Res Pract Thromb Haemost 2019;3(04): 615-625

8 Hayward CPM, Moffat KA, Brunet J, et al. Update on diagnostic testing for platelet function disorders: What is practical and useful? Int J Lab Hematol 2019;41(Suppl 1):26-32

9 George JN, Caen JP, Nurden AT. Glanzmann's thrombasthenia: the spectrum of clinical disease. Blood 1990;75(07):1383-1395

10 Harrison P, Mackie I, Mumford A, et al; British Committee for Standards in Haematology. Guidelines for the laboratory investigation of heritable disorders of platelet function. $\mathrm{Br} \mathrm{J}$ Haematol 2011;155(01):30-44
11 Gresele PSubcommittee on Platelet Physiology of the International Society on Thrombosis and Hemostasis. Diagnosis of inherited platelet function disorders: guidance from the SSC of the ISTH. J Thromb Haemost 2015;13(02):314-322

12 Alessi M-C, Sié P, Payrastre B. Strengths and weaknesses of light transmission aggregometry in diagnosing hereditary platelet function disorders. J Clin Med 2020;9(03):E763

13 Cattaneo M, Cerletti C, Harrison P, et al. Recommendations for the standardization of light transmission aggregometry: a consensus of the working party from the Platelet Physiology Subcommittee of SSC/ISTH. J Thromb Haemost 2013. Doi: 10.1111/ jth.12231 (epub ahead of print)

14 Linnemann B, Schwonberg J, Mani H, Prochnow S, Lindhoff-Last E. Standardization of light transmittance aggregometry for monitoring antiplatelet therapy: an adjustment for platelet count is not necessary. J Thromb Haemost 2008;6(04):677-683

15 Cattaneo M, Lecchi A, Zighetti ML, Lussana F. Platelet aggregation studies: autologous platelet-poor plasma inhibits platelet aggregation when added to platelet-rich plasma to normalize platelet count. Haematologica 2007;92(05):694-697

16 Robert P, Canault M, Farnarier C, et al. A novel leukocyte adhesion deficiency III variant: kindlin-3 deficiency results in integrinand nonintegrin-related defects in different steps of leukocyte adhesion. J Immunol 2011;186(09):5273-5283

17 Canault M, Ghalloussi D, Grosdidier C, et al. Human CalDAG-GEFI gene (RASGRP2) mutation affects platelet function and causes severe bleeding. J Exp Med 2014;211(07):1349-1362

18 Quinton TM, Kim S, Dangelmaier C, et al. Protein kinase C- and calcium-regulated pathways independently synergize with $\mathrm{Gi}$ pathways in agonist-induced fibrinogen receptor activation. Biochem J 2002;368(Pt 2):535-543

19 Quinton TM, Ozdener F, Dangelmaier C, Daniel JL, Kunapuli SP. Glycoprotein VI-mediated platelet fibrinogen receptor activation occurs through calcium-sensitive and PKC-sensitive pathways without a requirement for secreted ADP. Blood 2002;99 (09):3228-3234

20 Stefanini L, Roden RC, Bergmeier W. CalDAG-GEFI is at the nexus of calcium-dependent platelet activation. Blood 2009;114(12): 2506-2514

21 Canault M, Alessi M-C. RasGRP2 structure, function and genetic variants in platelet pathophysiology. Int J Mol Sci 2020;21(03): E1075

22 Lecchi A, Razzari C, Paoletta S, et al. Identification of a new dysfunctional platelet P2Y12 receptor variant associated with bleeding diathesis. Blood 2015;125(06):1006-1013

23 Cattaneo M, Lecchi A, Randi AM, McGregor JL, Mannucci PM. Identification of a new congenital defect of platelet function characterized by severe impairment of platelet responses to adenosine diphosphate. Blood 1992;80(11):2787-2796

24 Patel YM, Lordkipanidzé M, Lowe GC, et al. A novel mutation in the P2Y12 receptor and a function-reducing polymorphism in protease-activated receptor 1 in a patient with chronic bleeding. J Thromb Haemost 2014;12(05):716-725

25 Shiraga M, Miyata S, Kato H, et al. Impaired platelet function in a patient with P2Y12 deficiency caused by a mutation in the translation initiation codon. J Thromb Haemost 2005;3(10): 2315-2323

26 Dawood BB, Lowe GC, Lordkipanidzé M, et al. Evaluation of participants with suspected heritable platelet function disorders including recommendation and validation of a streamlined agonist panel. Blood 2012;120(25):5041-5049

27 Berrou E, Soukaseum C, Favier R, et al. A mutation of the human $E P H B 2$ gene leads to a major platelet functional defect. Blood 2018;132(19):2067-2077

28 Bellio M, Garcia C, Edouard T, et al. Catalytic dysregulation of SHP2 leading to Noonan syndromes affects platelet signaling and functions. Blood 2019;134(25):2304-2317 
29 Andrews RK, Berndt MC. Bernard-Soulier syndrome: an update. Semin Thromb Hemost 2013;39(06):656-662

30 Takahashi H, Sakuragawa N, Shibata A. Von Willebrand disease with an increased ristocetin-induced platelet aggregation and a qualitative abnormality of the factor VIII protein. Am J Hematol 1980;8(03):299-308

31 Othman M. Platelet-type von Willebrand disease: a rare, often misdiagnosed and underdiagnosed bleeding disorder. Semin Thromb Hemost 2011;37(05):464-469

32 Freson K, Hoylaerts MF, Jaeken J, et al. Genetic variation of the extra-large stimulatory $G$ protein alpha-subunit leads to Gs hyperfunction in platelets and is a risk factor for bleeding. Thromb Haemost 2001;86(03):733-738

33 Cardinal DC, Flower RJ. The electronic aggregometer: a novel device for assessing platelet behavior in blood. J Pharmacol Methods 1980;3(02):135-158

34 Fritsma GA, McGlasson DL. Whole Blood Platelet Aggregometry. Methods Mol Biol 2017;1646:333-347

35 Sweeney JD, Hoernig LA, Michnik A, Fitzpatrick JE. Whole blood aggregometry. Influence of sample collection and delay in study performance on test results. Am J Clin Pathol 1989;92(05): 676-679

36 Sweeney JD, Labuzetta JW, Fitzpatrick JE. The effect of the platelet count on the aggregation response and adenosine triphosphate release in an impedance lumi-aggregometer. Am J Clin Pathol 1988;89(05):655-659

37 Dyszkiewicz-Korpanty AM, Frenkel EP, Sarode R. Approach to the assessment of platelet function: comparison between opticalbased platelet-rich plasma and impedance-based whole blood platelet aggregation methods. Clin Appl Thromb Hemost 2005; 11(01):25-35

38 Albanyan A, Al-Musa A, AlNounou R, et al. Diagnosis of Glanzmann thrombasthenia by whole blood impedance analyzer (MEA) vs. light transmission aggregometry. Int J Lab Hematol 2015;37(04):503-508

39 Awidi A, Maqablah A, Dweik M, Bsoul N, Abu-Khader A. Comparison of platelet aggregation using light transmission and multiple electrode aggregometry in Glanzmann thrombasthenia. Platelets 2009;20(05):297-301

40 Quick AJ. The bleeding time as a test of hemostatic function. Am J Clin Pathol 1975;64(01):87-94

41 Rodgers RP, Levin J. A critical reappraisal of the bleeding time. Semin Thromb Hemost 1990;16(01):1-20

42 Favaloro EJ. Clinical utility of closure times using the platelet function analyzer-100/200. Am J Hematol 2017;92(04):398-404

43 Mulliez SMN, Hallaert G, Van Roost D, Vantilborgh A, Devreese KMJ. Influence of platelet clumps on platelet function analyser (PFA)-200® testing. Int J Lab Hematol 2015;37(05):e103-e105

44 Favaloro EJ. Utility of the platelet function analyser (PFA$100 / 200$ ) for exclusion or detection of von Willebrand disease: a study 22 years in the making. Thromb Res 2020;188:17-24

45 Kerényi A, Schlammadinger A, Ajzner E, et al. Comparison of PFA100 closure time and template bleeding time of patients with inherited disorders causing defective platelet function. Thromb Res 1999;96(06):487-492

46 Shenkman B, Einav Y, Salomon O, Varon D, Savion N. Testing agonist-induced platelet aggregation by the Impact-R [Cone and plate(let) analyzer (CPA)]. Platelets 2008;19(06):440-446

47 Paniccia R, Priora R, Liotta AA, Abbate R. Platelet function tests: a comparative review. Vasc Health Risk Manag 2015;11:133-148

48 Campbell J, Ridgway H, Carville D. Plateletworks: a novel point of care platelet function screen. Mol Diagn Ther 2008;12(04): 253-258

49 Barg AA, Hauschner H, Misgav M, et al. A novel approach using ancillary tests to guide treatment of Glanzmann thrombasthenia patients undergoing surgical procedures. Blood Cells Mol Dis 2018;72:44-48
50 Grassetto A, Fullin G, Lazzari F, et al. Perioperative ROTEM and ROTEM platelet monitoring in a case of Glanzmann's thrombasthenia. Blood Coagul Fibrinolysis 2017;28(01):96-99

51 Whiting D, DiNardo JA. TEG and ROTEM: technology and clinical applications. Am J Hematol 2014;89(02):228-232

52 Savage B, Saldívar E, Ruggeri ZM. Initiation of platelet adhesion by arrest onto fibrinogen or translocation on von Willebrand factor. Cell 1996;84(02):289-297

53 Mangin PH, Gardiner EE, Nesbitt WS, et al; Subcommittee on Biorheology. In vitro flow based systems to study platelet function and thrombus formation: Recommendations for standardization: communication from the SSC on Biorheology of the ISTH. J Thromb Haemost 2020;18(03):748-752

54 Hézard N, Potron G, Schlegel N, Amory C, Leroux B, Nguyen P. Unexpected persistence of platelet hyporeactivity beyond the neonatal period: a flow cytometric study in neonates, infants and older children. Thromb Haemost 2003;90(01):116-123

55 Ignatova AA, Ponomarenko EA, Polokhov DM, et al. Flow cytometry for pediatric platelets. Platelets 2019;30(04):428-437

56 Nomura S, Nagata H, Kitada T, et al. [Analysis of Glanzmann's thrombasthenia and Bernard-Soulier syndrome using flow cytometry]. Rinsho Ketsueki 1987;28(03):377-385

57 Jennings LK, Ashmun RA, Wang WC, Dockter ME. Analysis of human platelet glycoproteins IIb-IIla and Glanzmann's thrombasthenia in whole blood by flow cytometry. Blood 1986;68(01): 173-179

58 Handa M, Watanabe K, Kawai Y, et al. Platelet unresponsiveness to collagen: involvement of glycoprotein Ia-IIa (alpha 2 beta 1 integrin) deficiency associated with a myeloproliferative disorder. Thromb Haemost 1995;73(03):521-528

59 van Asten I, Schutgens REG, Urbanus RT. Toward flow cytometry based platelet function diagnostics. Semin Thromb Hemost 2018;44(03):197-205

60 Pasalic L, Pennings GJ, Connor D, Campbell H, Kritharides L, Chen VM. Flow cytometry protocols for assessment of platelet function in whole blood. Methods Mol Biol 2017;1646:369-389

61 Sims PJ, Wiedmer T, Esmon CT, Weiss HJ, Shattil SJ. Assembly of the platelet prothrombinase complex is linked to vesiculation of the platelet plasma membrane. Studies in Scott syndrome: an isolated defect in platelet procoagulant activity. J Biol Chem 1989;264(29):17049-17057

62 Prodan CI, Joseph PM, Vincent AS, Dale GL. Coated-platelet levels are influenced by smoking, aspirin, and selective serotonin reuptake inhibitors. J Thromb Haemost 2007;5(10):2149-2151

63 Dale GL. Coated-platelets: an emerging component of the procoagulant response. J Thromb Haemost 2005;3(10):2185-2192

64 Abaeva AA, Canault M, Kotova YN, et al. Procoagulant platelets form an $\alpha$-granule protein-covered "cap" on their surface that promotes their attachment to aggregates. J Biol Chem 2013;288 (41):29621-29632

65 Prodan CI, Stoner JA, Dale GL. Lower coated-platelet levels are associated with increased mortality after spontaneous intracerebral hemorrhage. Stroke 2015;46(07):1819-1825

66 Colucci G, Stutz M, Rochat S, et al. The effect of desmopressin on platelet function: a selective enhancement of procoagulant COAT platelets in patients with primary platelet function defects. Blood 2014;123(12):1905-1916

67 Brooks MB, Catalfamo JL, Friese P, Dale GL. Scott syndrome dogs have impaired coated-platelet formation and calcein-release but normal mitochondrial depolarization. J Thromb Haemost 2007;5 (09):1972-1974

68 Saxena K, Pethe K, Dale GL. Coated-platelet levels may explain some variability in clinical phenotypes observed with severe hemophilia. J Thromb Haemost 2010;8(05):1140-1142

69 Kirkpatrick AC, Vincent AS, Dale GL, Prodan CI. Increased platelet procoagulant potential predicts recurrent stroke and TIA after lacunar infarction. J Thromb Haemost 2020;18(03):660-668 
70 Zighetti ML, Carpani G, Sinigaglia E, Cattaneo M. Usefulness of a flow cytometric analysis of intraplatelet vasodilator-stimulated phosphoprotein phosphorylation for the detection of patients with genetic defects of the platelet P2Y(12) receptor for ADP. J Thromb Haemost 2010;8(10):2332-2334

71 Gachet C. P2 receptors, platelet function and pharmacological implications. Thromb Haemost 2008;99(03):466-472

72 Murugappa S, Kunapuli SP. The role of ADP receptors in platelet function. Front Biosci 2006;11:1977-1986

73 Cattaneo M, Canciani MT, Lecchi A, et al. Released adenosine diphosphate stabilizes thrombin-induced human platelet aggregates. Blood 1990;75(05):1081-1086

74 Sandrock-Lang K, Wentzell R, Santoso S, Zieger B. Inherited platelet disorders. Hamostaseologie 2016;36(03):178-186

75 Sharda A, Flaumenhaft R. The life cycle of platelet granules. F1000 Res 2018;7:236

76 Israels SJ, El-Ekiaby M, Quiroga T, Mezzano D. Inherited disorders of platelet function and challenges to diagnosis of mucocutaneous bleeding. Haemophilia 2010;16(Suppl 5):152-159

77 Rand ML, Reddy EC, Israels SJ. Laboratory diagnosis of inherited platelet function disorders. Transfus Apheresis Sci 2018;57(04): 485-493

78 Mezzano D, Quiroga T. Diagnostic challenges of inherited mild bleeding disorders: a bait for poorly explored clinical and basic research. J Thromb Haemost 2019;17(02):257-270

79 Cattaneo M. Light transmission aggregometry and ATP release for the diagnostic assessment of platelet function. Semin Thromb Hemost 2009;35(02):158-167

80 Callan MB, Bennett JS, Phillips DK, et al. Inherited platelet deltastorage pool disease in dogs causing severe bleeding: an animal model for a specific ADP deficiency. Thromb Haemost 1995;74 (03):949-953

81 Cortese M, Delporte C, Dufour D, et al. Validation of a LC/MSMS method for simultaneous quantification of 9 nucleotides in biological matrices. Talanta 2019;193:206-214

82 Pai M, Wang G, Moffat KA, et al. Diagnostic usefulness of a lumiaggregometer adenosine triphosphate release assay for the assessment of platelet function disorders. Am J Clin Pathol 2011;136(03):350-358

83 Badin MS, Graf L, Iyer JK, Moffat KA, Seecharan JL, Hayward CPM. Variability in platelet dense granule adenosine triphosphate release findings amongst patients tested multiple times as part of an assessment for a bleeding disorder. Int J Lab Hematol 2016;38(06):648-657

84 Saultier P, Vidal L, Canault M, et al. Macrothrombocytopenia and dense granule deficiency associated with FLI1 variants: ultrastructural and pathogenic features. Haematologica 2017;102 (06):1006-1016

85 Andres O, Wiegering V, König E-M, et al. A novel two-nucleotide deletion in HPS6 affects mepacrine uptake and platelet dense granule secretion in a family with Hermansky-Pudlak syndrome. Pediatr Blood Cancer 2017;64(05):. Doi: 10.1002/pbc.26320

86 Cai H, Mullier F, Frotscher B, et al. Usefulness of flow cytometric mepacrine uptake/release combined with CD63 assay in diagnosis of patients with suspected platelet dense granule disorder. Semin Thromb Hemost 2016;42(03):282-291

87 Billio A, Moeseneder C, Donazzan G, Triani A, Pescosta N, Coser P. Hermansky-Pudlak syndrome: clinical presentation and confirmation of the value of the mepacrine-based cytofluorimetry test in the diagnosis of delta granule deficiency. Haematologica 2001; 86(02):220

88 Wall JE, Buijs-Wilts M, Arnold JT, et al. A flow cytometric assay using mepacrine for study of uptake and release of platelet dense granule contents. Br J Haematol 1995;89(02):380-385

89 van Asten I, Blaauwgeers M, Granneman L, et al. Flow cytometric mepacrine fluorescence can be used for the exclusion of platelet dense granule deficiency.J Thromb Haemost 2020;18(03):706-713
90 Lorez HP, Richards JG, Da Prada M, et al. Storage pool disease: comparative fluorescence microscopical, cytochemical and biochemical studies on amine-storing organelles of human blood platelets. Br J Haematol 1979;43(02):297-305

91 Korse CM, Buning-Kager JCGM, Linders TC, et al. A serum and platelet-rich plasma serotonin assay using liquid chromatography tandem mass spectrometry for monitoring of neuroendocrine tumor patients. Clin Chim Acta 2017;469:130-135

92 Maurer-Spurej E, Dyker K, Gahl WA, Devine DV. A novel immunocytochemical assay for the detection of serotonin in platelets. Br J Haematol 2002;116(03):604-611

93 Quiroga T, Goycoolea M, Matus V, et al. Diagnosis of mild platelet function disorders. Reliability and usefulness of light transmission platelet aggregation and serotonin secretion assays. Br J Haematol 2009;147(05):729-736

94 Hayward CPM, Moffat KA, Spitzer E, et al; NASCOLA Working Group on Platelet Dense Granule Deficiency. Results of an external proficiency testing exercise on platelet dense-granule deficiency testing by whole mount electron microscopy. Am J Clin Pathol 2009;131(05):671-675

95 Brunet JG, Iyer JK, Badin MS, et al. Electron microscopy examination of platelet whole mount preparations to quantitate platelet dense granule numbers: Implications for diagnosing suspected platelet function disorders due to dense granule deficiency. Int J Lab Hematol 2018;40(04):400-407

96 Knight AE, Gomez K, Cutler DF. Super-resolution microscopy in the diagnosis of platelet granule disorders. Expert Rev Hematol 2017;10(05):375-381

97 Nurden AT, Nurden P. Congenital platelet disorders and understanding of platelet function. Br J Haematol 2014;165(02): $165-178$

98 Gunay-Aygun M, Huizing M, Gahl WA. Molecular defects that affect platelet dense granules. Semin Thromb Hemost 2004;30 (05):537-547

99 Wei ML. Hermansky-Pudlak syndrome: a disease of protein trafficking and organelle function. Pigment Cell Res 2006;19 (01):19-42

100 Introne W, Boissy RE, Gahl WA. Clinical, molecular, and cell biological aspects of Chediak-Higashi syndrome. Mol Genet Metab 1999;68(02):283-303

101 White JG, Thomas A. Platelet structural pathology in a patient with the X-linked GATA-1, R216Q mutation. Platelets 2009;20 (01):41-49

102 Mao GF, Goldfinger LE, Fan DC, et al. Dysregulation of PLDN (pallidin) is a mechanism for platelet dense granule deficiency in RUNX1 haplodeficiency. J Thromb Haemost 2017;15(04): 792-801

103 Berrou E, Adam F, Lebret M, et al. Heterogeneity of platelet functional alterations in patients with filamin A mutations. Arterioscler Thromb Vasc Biol 2013;33(01):e11-e18

104 Nurden AT, Nurden P. The gray platelet syndrome: clinical spectrum of the disease. Blood Rev 2007;21(01):21-36

105 Zhou Y, Zhang J. Arthrogryposis-renal dysfunction-cholestasis (ARC) syndrome: from molecular genetics to clinical features. Ital J Pediatr 2014;40:77

106 Spurgeon BEJ, Aburima A, Oberprieler NG, Taskén K, Naseem KM. Multiplexed phosphospecific flow cytometry enables large-scale signaling profiling and drug screening in blood platelets. J Thromb Haemost 2014;12(10):1733-1743

107 Greinacher A, Pecci A, Kunishima S, et al. Diagnosis of inherited platelet disorders on a blood smear: a tool to facilitate worldwide diagnosis of platelet disorders. J Thromb Haemost 2017;15(07): 1511-1521

108 FitzGerald GA, Brash AR, Oates JA, Pedersen AK. Endogenous prostacyclin biosynthesis and platelet function during selective inhibition of thromboxane synthase in man.J Clin Invest 1983;72 (04):1336-1343 
109 Muir AR, McMullin MF, Patterson C, McKeown PP. Assessment of aspirin resistance varies on a temporal basis in patients with ischaemic heart disease. Heart 2009;95(15):1225-1229

110 Gremmel T, Perkmann T, Seidinger D, et al. Differential impact of inflammation on six laboratory assays measuring residual arachidonic acid-inducible platelet reactivity during dual antiplatelet therapy. J Atheroscler Thromb 2013;20(07):630-645

111 Hayward CP, Rivard GE, Kane WH, et al. An autosomal dominant, qualitative platelet disorder associated with multimerin deficiency, abnormalities in platelet factor $\mathrm{V}$, thrombospondin, von Willebrand factor, and fibrinogen and an epinephrine aggregation defect. Blood 1996;87(12):4967-4978

112 Diamandis M, Paterson AD, Rommens JM, et al. Quebec platelet disorder is linked to the urokinase plasminogen activator gene
(PLAU) and increases expression of the linked allele in megakaryocytes. Blood 2009;113(07):1543-1546

113 Kahr WH, Zheng S, Sheth PM, et al. Platelets from patients with the Quebec platelet disorder contain and secrete abnormal amounts of urokinase-type plasminogen activator. Blood 2001;98(02):257-265

114 Diamandis M, Adam F, Kahr WHA, et al. Insights into abnormal hemostasis in the Quebec platelet disorder from analyses of clot lysis. J Thromb Haemost 2006;4(05):1086-1094

115 Freson K, Turro E. High-throughput sequencing approaches for diagnosing hereditary bleeding and platelet disorders. J Thromb Haemost 2017;15(07):1262-1272 